\title{
A data mining approach to investigate food groups related to incidence of bladder cancer in the BLadder cancer Epidemiology and Nutritional Determinants International Study
}

Citation for published version (APA):

Yu, E. Y. W., Wesselius, A., Sinhart, C., Wolk, A., Stern, M. C., Jiang, X., Tang, L., Marshall, J., Kellen, E., van den Brandt, P., Lu, C-M., Pohlabeln, H., Steineck, G., Allam, M. F., Karagas, M. R., La Vecchia, C., Porru, S., Carta, A., Golka, K., ... Zeegers, M. P. A. (2020). A data mining approach to investigate food groups related to incidence of bladder cancer in the BLadder cancer Epidemiology and Nutritional Determinants International Study. British Journal of Nutrition, 124(6), 611-619. [0007114520001439]. https://doi.org/10.1017/S0007114520001439

Document status and date:

Published: 28/09/2020

DOI:

10.1017/S0007114520001439

Document Version:

Publisher's PDF, also known as Version of record

Document license:

Taverne

Please check the document version of this publication:

- A submitted manuscript is the version of the article upon submission and before peer-review. There can be important differences between the submitted version and the official published version of record. People interested in the research are advised to contact the author for the final version of the publication, or visit the DOI to the publisher's website.

- The final author version and the galley proof are versions of the publication after peer review.

- The final published version features the final layout of the paper including the volume, issue and page numbers.

Link to publication

\footnotetext{
General rights rights.

- You may freely distribute the URL identifying the publication in the public portal. please follow below link for the End User Agreement:

www.umlib.nl/taverne-license

Take down policy

If you believe that this document breaches copyright please contact us at:

repository@maastrichtuniversity.nl

providing details and we will investigate your claim.
}

Copyright and moral rights for the publications made accessible in the public portal are retained by the authors and/or other copyright owners and it is a condition of accessing publications that users recognise and abide by the legal requirements associated with these

- Users may download and print one copy of any publication from the public portal for the purpose of private study or research.

- You may not further distribute the material or use it for any profit-making activity or commercial gain

If the publication is distributed under the terms of Article 25fa of the Dutch Copyright Act, indicated by the "Taverne" license above, 


\section{A data mining approach to investigate food groups related to incidence of bladder cancer in the BLadder cancer Epidemiology and Nutritional Determinants International Study}

Evan Y. W. Yu ${ }^{1}$, Anke Wesselius ${ }^{1 *}$, Christoph Sinhart ${ }^{2}$, Alicja Wolk ${ }^{3}$, Mariana Carla Stern ${ }^{4}$, Xuejuan Jiang ${ }^{4}$, Li Tang $^{5}$, James Marshall ${ }^{5}$, Eliane Kellen ${ }^{6}$, Piet van den Brandt ${ }^{7}$, Chih-Ming Lu ${ }^{8}$, Hermann Pohlabeln ${ }^{9}$, Gunnar Steineck ${ }^{10}$, Mohamed Farouk Allam ${ }^{11}$, Margaret R. Karagas ${ }^{12}$, Carlo La Vecchia ${ }^{13}$, Stefano Porru ${ }^{14,15}$, Angela Carta ${ }^{15,16}$, Klaus Golka ${ }^{17}$, Kenneth C. Johnson ${ }^{18}$, Simone Benhamou ${ }^{19}$, Zuo-Feng Zhang ${ }^{20}$, Cristina Bosetti ${ }^{21}$, Jack A. Taylor ${ }^{22}$, Elisabete Weiderpass ${ }^{23}$, Eric J. Grant ${ }^{24}$, Emily White ${ }^{25}$, Jerry Polesel ${ }^{26}$ and Maurice P. A. Zeegers ${ }^{27,28}$

${ }^{1}$ Department of Complex Genetics and Epidemiology, School of Nutrition and Translational Research in Metabolism, Maastricht University, Maastricht, The Netherlands

${ }^{2}$ Department of Data Science E Knowledge Engineering, Faculty of Science and Engineering, Maastricht University, Maastricht, The Netherlands

${ }^{3}$ Division of Nutritional Epidemiology, Institute of Environmental Medicine, Karolinska Institute, Stockholm, Sweden

${ }^{4}$ Department of Preventive Medicine, University of Southern California, Los Angeles, CA, USA

${ }^{5}$ Department of Cancer Prevention and Control, Roswell Park Cancer Institute, Buffalo, NY, USA

${ }^{6}$ Leuven University Centre for Cancer Prevention (LUCK), Leuven, Belgium

${ }^{7}$ Department of Epidemiology, Schools for Oncology and Developmental Biology and Public Health and Primary Care,

Maastricht University Medical Centre, Maastricht, The Netherlands

${ }^{8}$ Department of Urology, Buddhist Dalin Tzu Chi General Hospital, Dalin Township 62247, Chiayi County, Taiwan

${ }^{9}$ Leibniz Institute for Prevention Research and Epidemiology-BIPS, Bremen, Germany

${ }^{10}$ Department of Oncology and Pathology, Division of Clinical Cancer Epidemiology, Karolinska Hospital, Stockholm, Sweden

${ }^{11}$ Department of Preventive Medicine and Public Health, Faculty of Medicine, University of Cordoba, Cordoba, Spain

${ }^{12}$ Department of Epidemiology, Geisel School of Medicine at Dartmouth, Hanover, NH, USA

${ }^{13}$ Department of Clinical Medicine and Community Health, University of Milan, Milan, Italy

${ }^{14}$ Department of Diagnostics and Public Health, Section of Occupational Health, University of Verona, Verona, Italy

${ }^{15}$ University Research Center 'Integrated Models for Prevention and Protection in Environmental and Occupational Health'

MISTRAL, University of Verona, Milano Bicocca and Brescia, Italy

${ }^{16}$ Department of Medical and Surgical Specialties, Radiological Sciences and Public Health, University of Brescia, Brescia, Italy

${ }^{17}$ Leibniz Research Centre for Working Environment and Human Factors at TU Dortmund, Dortmund, Germany

${ }^{18}$ Department of Epidemiology and Community Medicine, University of Ottawa, Ottawa, ON, Canada

${ }^{19}$ INSERM U946, Variabilite Genetique et Maladies Humaines, Fondation Jean Dausset/CEPH, Paris, France

${ }^{20}$ Departments of Epidemiology, UCLA Center for Environmental Genomics, Fielding School of Public Health, University of

California, Los Angeles (UCLA), Los Angeles, CA, USA

${ }^{21}$ Department of Oncology, Istituto di Ricerche Farmacologiche Mario Negri-IRCCS, Milan, Italy

${ }^{22}$ Epidemiology Branch, and Epigenetic and Stem Cell Biology Laboratory, National Institute of Environmental Health Sciences,

NIH, Research Triangle Park, NC, USA

${ }^{23}$ International Agency for Research on Cancer (IARC), World Health Organization, Lyon, France

${ }^{24}$ Department of Epidemiology Radiation Effects Research Foundation, Hiroshima, Japan

${ }^{25}$ Fred Hutchinson Cancer Research Center, Seattle, WA, USA

${ }^{26}$ Unit of Cancer Epidemiology, Centro di Riferimento Oncologico di Aviano (CRO) IRCCS, Aviano, Italy

${ }^{27}$ CAPHRI School for Public Health and Primary Care, University of Maastricht, Maastricht, The Netherlands

${ }^{28}$ School of Cancer Sciences, University of Birmingham, Birmingham, UK

(Submitted 1 November 2019 - Final revision received 10 April 2020 - Accepted 14 April 2020 - First published online 23 April 2020)

Abbreviations: BC, bladder cancer; BLEND, BLadder cancer Epidemiology and Nutritional Determinants; MAR, missing at random; MCAR, missing completely at random.

* Corresponding author: Anke Wesselius, email anke.wesselius@maastrichtuniversity.nl 


\section{Abstract}

At present, analysis of diet and bladder cancer (BC) is mostly based on the intake of individual foods. The examination of food combinations provides a scope to deal with the complexity and unpredictability of the diet and aims to overcome the limitations of the study of nutrients and foods in isolation. This article aims to demonstrate the usability of supervised data mining methods to extract the food groups related to BC. In order to derive key food groups associated with BC risk, we applied the data mining technique C5.0 with 10-fold cross-validation in the BLadder cancer Epidemiology and Nutritional Determinants study, including data from eighteen case-control and one nested case-cohort study, compromising $8320 \mathrm{BC}$ cases out of 31551 participants. Dietary data, on the eleven main food groups of the Eurocode 2 Core classification codebook, and relevant non-diet data (i.e. sex, age and smoking status) were available. Primarily, five key food groups were extracted; in order of importance, beverages (non-milk); grains and grain products; vegetables and vegetable products; fats, oils and their products; meats and meat products were associated with BC risk. Since these food groups are corresponded with previously proposed BC-related dietary factors, data mining seems to be a promising technique in the field of nutritional epidemiology and deserves further examination.

\section{Key words: Bladder cancer: Data mining: Food groups: Epidemiological studies}

Bladder cancer (BC) is the most common malignancy of urinary tract and the seventh cause of mortality for cancer $(2 \cdot 8 \%$ of all cancer deaths), with nearly 430000 new cases and 165000 deaths per year worldwide ${ }^{(1,2)}$. According to Al-Zalabani et al., up to $80 \%$ of $\mathrm{BC}$ can be attributed to lifestyles, including occupation, smoking, exercise and $\operatorname{diet}^{(3)}$. Particularly, it is biologically plausible for dietary factors to influence BC risk considering that beneficial as well as harmful components of a diet are excreted through the urinary tract and in direct contact with the epithelium of the bladder ${ }^{(4)}$. However, as stated in the report by World Cancer Research Fund/American Institute for Cancer Research ${ }^{(5)}$, there is still 'limited' evidence for the role of diet on the $\mathrm{BC}$ risk.

Analysis of overall dietary patterns related to $\mathrm{BC}$ has gained a lot of attention during past years ${ }^{(6,7)}$. Instead of looking at individual foods or nutrients, analysis of dietary patterns examines the effects of the overall diet, considering the inter-correlations in the consumption of various foods and nutrients. Conceptually, dietary patterns represent a broader picture of food and nutrient consumption, and analysis of dietary patterns may help in better understanding and preventing the development of common cancers.

Several conventional analysis techniques are available for extracting dietary patterns including factor and cluster analyses: investigator-driven methods, such as dietary indices and dietary scores; and data-driven methods, such as principal component analysis. Although these techniques are widely used and might reveal some important information on the relation between dietary patterns and common cancers, they all draw subjective conclusions since they are based on series of a priori assumptions, which may differ among researchers. A relatively new approach in the field of nutritional epidemiology is 'data mining'. Data mining is a process that uses a variety of data analysis tools to extract hidden predictive information from large data. This technique is considered to be a powerful technology with great potential to help people focus on the most important information of their data ${ }^{(8)}$. A previous study in the field of nutritional epidemiology already showed that data mining allowed to define unexpected dietary patterns that might not be recognised using conventional statistical methods ${ }^{(9)}$. Therefore, in the present study, we used this technique to examine the combinational foods at individual level to extract some food groups related to the $\mathrm{BC}$ risk.

\section{Methods}

\section{Study population}

The data set used in the present study is part of the 'BLadder cancer Epidemiology and Nutritional Determinant (BLEND)' study, which aims at assessing the association between diet and the BC risk. Details on the methodology of the BLEND consortium have been described elsewhere ${ }^{(10)}$. The present study included data of eighteen case-control ${ }^{(11-28)}$ and one nested case-cohort study ${ }^{(29)}$ providing information on diet and $\mathrm{BC}$, from twelve different countries across the world, including data on $8320 \mathrm{BC}$ cases and 23231 non-cases within the age range of 18-100 years. Each study ascertained incident BC defined to include all urinary bladder neoplasms according to the International Classification of Diseases for Oncology (ICD-O-3 code C67) using population-based cancer registries, health insurance records or medical records. Each participating study has been approved by the local ethic committee. Informed consent was obtained from all individual participants included in each study. Most of the $\mathrm{BC}$ cases were diagnosed and histologically confirmed in 1990s.

\section{Data collection}

All included studies made use of a validated self-administrated FFQ or an FFQ administered by a trained interviewer. Homogenisation of the dietary data was done by making use of the Eurocode 2 Core classification $\operatorname{codebook}^{(30)}$. This codebook consists of main food groups and their first- and secondlevel subgroups ${ }^{(31)}$. In order to reduce the variance of individual food items across the world (online Supplementary Table S1), foods were attributed into eleven main groups: milk and dairy products (A); eggs and egg products (B); meats and meat products (C); fishes and fish products (D); fats, oils and their products (E); grains and grain products $(\mathrm{F})$; pulses, seeds, kernels, nuts and their products $(G)$; vegetables and vegetable products $(\mathrm{H})$; fruits and fruit products (I); sugars and sugar products (J); and beverages (non-milk, K). All food groups were measured as servings of food intake per week and divided into quartile, with Q1-Q4 corresponding to lowest and highest intake. In addition to information on diet, the BLEND data set also included data on study characteristics (design, method of dietary 
assessment and geographical region) and participant demographics (age (continuous), sex (male, female)) and smoking status (never/current/former).

\section{Baseline analysis}

Continuous variables were described as mean and standard deviation, and categorical variables as absolute and relative frequencies. Missing values were tested for missing at random (MAR) or missing completely at random (MCAR) ${ }^{(32,33)}$. To test for MAR, logistic regression was performed with a missing data indicator created for each variable. No significant relationship between the missingness indicators and the outcome of interest suggests MAR. The assumption that missing data are MCAR was assessed using Little's MCAR $\chi^{2}$ test ${ }^{(34,35)}$

\section{Data mining method}

All the eleven main food groups and the non-diet variables (i.e. age, sex and smoking status) were selected and entered into data mining procedures.

A classification technique called C $5.0^{(36)}$, which is a variant of the C4.5 algorithm developed by Ross Quinlan, was used since it can represent solutions as decision trees and as rulesets ${ }^{(37)}$. It builds a decision tree based on the training/validation sets using the concept of information entropy. The decision tree is built by splitting the data into two parts at the value of one variable that yields the highest normalised information gain. That is, it splits on the value of the chosen variable that separates positive and negative observations (i.e. BC status: case and noncase), most efficiently. The pruning severity of the model was set at the default level of 75 . This level yielded the lowest complexity (i.e. which refers to the minimum number of records in each tree branch to allow a split) with sufficient accuracy. Standard 10-fold cross-validation was used in which the entire eligible BLEND data set was divided into ten approximately equally sized parts. Nine parts were used in turn as training sets, and the remaining tenth part was used as the validation set. The validation set (10\%) was chosen within the entire data set according to the distribution of BC status. The participants with missing values were taken into account by using the ratio of the participants with missing values multiplied by the information entropy of the subset of participants without missing values for each variable $^{(38)}$. The classification C5.0 algorithm was run for the included diet and non-diet variables within the BLEND data set; meanwhile, variable importance (i.e. attribute usage) for the C5.0 model was calculated by determining the percentage of training set samples that fall into all the terminal nodes after the split, which defines the variable importance value of each diet and non-diet variables in relation to $\mathrm{BC}^{(39-42)}$. These importance values range from 0 to $100 \%$, where $0 \%$ indicates 'unimportant' and $100 \%$ indicates 'extremely important'. Both continuous and categorical variables were included in the models. Node splits in continuous variables can occur at any value and were not predetermined.

Rules were then generated by using the 'ruleset' function in C5.0, which transformed the decision tree into specific context associated with BC. The BC status (either case or non-case) was predicted by each rule, and a value between 0 and $100 \%$ indicates the confidence of the risk in relation to $\mathrm{BC}$ outcome. The overall performance of the C5.0 classifier was evaluated by classification accuracy, true positive rate, false positive rate and receiver operating characteristic with the AUC. This is the number of correct classifications of the instances from the validation set divided by the total number of these instances, expressed as a percentage. The greater the classification accuracy, the better is the classifier. A sensitivity analysis was performed by categorising age into six groups (years): $\leq 55$, $55-60,60-65,65-70,70-75$ and $>75$, based on the same data mining procedure.

All data analyses were performed with $\mathrm{R}$ software version 3.5.1 (using packages 'C5.0' and 'caret' developed by Max Kuhn; 'rpart' developed by Beth Atkison; 'ROCR' developed by Tobias Sing and Oliver Sander).

\section{Results}

\section{Baseline analyses of the included data}

The characteristics of the BLEND participants are presented in Table 1. In total, 31551 participants are included in the analyses, of which $8320(26.37 \%)$ were BC cases. The mean age of non-cases ( 59 years old) was lower than cases (62 years old), and most of the participants were Caucasian (92.27\%). Approximately $66.68 \%$ of participants were smokers, with $33.62 \%$ of those being current smokers and $33.06 \%$ being former smokers.

Significant results of logistic regression for food-group variables indicated that missing dietary data were not MAR (all $P_{\text {MAR }}<0.05$ ). Little's test also provided evidence against the assumption that missing data were MCAR (all $P_{\mathrm{MCAR}}<0 \cdot 001$ ). Rejection of both MAR and MCAR indicates the missing values are missing not at random. Therefore, the observations with missing data could not be deleted, and the missing values were marked as blank and not replaced by any value.

\section{Extraction of food groups in relation to bladder cancer via the data mining procedure}

Fig. 1 presents an example of a decision tree with three different variables. The variables are ranked according to how they were used to split the participants from decision nodes to end nodes. The position of 1 (A) corresponds to the variable that in all trees is the first variable used to split; the position of 2 (B) corresponds to the variable that on average is the second variable used to spit, and so on till finally, all the participants were split into BC cases and non-cases. 'Sex' is on the first rank split of the tree, which indicates dietary patterns are differentiated in males and females related to $\mathrm{BC}$. Both non-diet variables (age, sex and smoking status) and five food groups (C, E, F, H and K) were identified as having an influence on the development of BC. The observed importance values of these variables are (Fig. 2): sex (100\%); smoking status (74.60\%); age (62.80\%); beverages (55.81\%); grains and grain products $(37.98 \%)$; vegetables and vegetable products (24.30\%); fats, oils and their products (2.95\%); meats and meat products $(2 \cdot 71 \%)$. Other input variables showed to have an importance value of $0 \%$ and were, therefore, considered non-relevant for $\mathrm{BC}$ development. The overall classification 
Table 1. Baseline characteristics and food group information from the BLadder cancer Epidemiology and Nutritional Determinants (BLEND) data set ${ }^{*}$ (Numbers and percentages; mean values and standard deviations)

\begin{tabular}{|c|c|c|c|c|c|c|}
\hline \multirow[b]{2}{*}{ Variables } & \multicolumn{3}{|c|}{ Cases ( $n$ 8320) } & \multicolumn{2}{|c|}{ Non-cases ( $n$ 23 231) } & \multirow[b]{2}{*}{ Missing percentage } \\
\hline & $n$ & & $\%$ & $n$ & $\%$ & \\
\hline Sex & & & & & & 0.00 \\
\hline Male & 6601 & & 33.95 & 12841 & 66.05 & \\
\hline Female & 1719 & & $14 \cdot 20$ & 10390 & 85.80 & \\
\hline Smoking & & & & & & 0.00 \\
\hline Never & 1588 & & $15 \cdot 11$ & 8925 & 84.89 & \\
\hline Current & 3285 & & 30.97 & 7321 & 69.03 & \\
\hline Former & 3447 & & 33.04 & 6985 & 66.96 & \\
\hline Age (years) & & & & & & 0.00 \\
\hline Mean & & 61.80 & & & & \\
\hline SD & & $10 \cdot 61$ & & & & \\
\hline$\leq 55$ & 1880 & & 20.46 & 7310 & 79.54 & \\
\hline $55-60$ & 1511 & & $26 \cdot 67$ & 4514 & 73.33 & \\
\hline $60-65$ & 1708 & & 28.22 & 4345 & 71.78 & \\
\hline $65-70$ & 1531 & & 27.97 & 3943 & 72.03 & \\
\hline $70-75$ & 1068 & & 31.23 & 2352 & 68.77 & \\
\hline$>75$ & 622 & & 35.56 & 1127 & 64.44 & \\
\hline \multicolumn{7}{|c|}{ Main food groups (mean servings/week) } \\
\hline Milk and milk products & & & & & & 4.47 \\
\hline Mean & & $13 \cdot 61$ & & & & \\
\hline SD & & $18 \cdot 39$ & & & & \\
\hline Q1: 0-5 servings/week† & 1887 & & $22 \cdot 14$ & 6632 & 79.86 & \\
\hline Q2: 5-9 servings/week & 1322 & & 19.93 & 5310 & 80.07 & \\
\hline Q3: 9-18 servings/week & 1626 & & 21.81 & 5828 & $78 \cdot 19$ & \\
\hline Q4: >18 servings/week & 1500 & & 19.92 & 6031 & 80.08 & \\
\hline Eggs and egg products & & & & & & 11.78 \\
\hline Mean & & 2.65 & & & & \\
\hline SD & & 2.89 & & & & \\
\hline Q1: 0-1 servings/week & 2117 & & 22.87 & 7141 & $77 \cdot 13$ & \\
\hline Q2: 1-2 servings/week & 1003 & & 18.89 & 4306 & $81 \cdot 11$ & \\
\hline Q3: 2-3 servings/week & 1246 & & 17.55 & 5852 & 82.45 & \\
\hline Q4: >3 servings/week & 1275 & & 26.05 & 4894 & 73.95 & \\
\hline Meat and meat products & & & & & & $7 \cdot 62$ \\
\hline Mean & & 7.75 & & & & \\
\hline SD & & 5.54 & & & & \\
\hline Q1: 0-5 servings/week & 1931 & & 24.41 & 5981 & 75.59 & \\
\hline Q2: 5-8 servings/week & 1810 & & 22.73 & 6154 & $77 \cdot 27$ & \\
\hline Q3: 8-11 servings/week & 1387 & & $21 \cdot 32$ & 6505 & 78.68 & \\
\hline Q4: >11 servings/week & 1298 & & 16.53 & 6555 & 83.47 & \\
\hline Fish and fish products & & & & & & $5 \cdot 72$ \\
\hline Mean & & 1.94 & & & & \\
\hline SD & & 2.08 & & & & \\
\hline Q1: 0-0.5 servings/week & 918 & & 24.41 & 7415 & 75.59 & \\
\hline Q2: $0.5-1$ servings/week & 1163 & & $12 \cdot 02$ & 8515 & 87.98 & \\
\hline Q3: 1-2 servings/week & 1387 & & 17.45 & 4287 & 82.55 & \\
\hline Q4: >2 servings/week & 1298 & & $19 \cdot 10$ & 5293 & 80.90 & \\
\hline Fats and oils & & & & & & 21.44 \\
\hline Mean & & $8 \cdot 61$ & & & & \\
\hline SD & & 7.98 & & & & \\
\hline Q1: 0-4 servings/week & 1291 & & 20.53 & 5641 & 79.47 & \\
\hline Q2: 4-7 servings/week & 1561 & & 23.79 & 5760 & $76 \cdot 21$ & \\
\hline Q3: 7-10 servings/week & 780 & & 13.49 & 5386 & 86.51 & \\
\hline Q4: >10 servings/week & 1152 & & 18.73 & 5654 & $81 \cdot 27$ & \\
\hline Grains and grain products & & & & & & $5 \cdot 36$ \\
\hline Mean & & $16 \cdot 17$ & & & & \\
\hline SD & & 17.33 & & & & \\
\hline Q1: 0-7 servings/week & 2061 & & $25 \cdot 80$ & 5928 & $74 \cdot 20$ & \\
\hline Q2: 7-13 servings/week & 1503 & & 21.63 & 5446 & $78 \cdot 37$ & \\
\hline Q3: 13-21 servings/week & 1494 & & 20.01 & 5973 & 79.99 & \\
\hline Q4: >21 servings/week & 1570 & & 21.06 & 5886 & 78.94 & \\
\hline Pulses, seeds, kernels and nuts & & & & & & 31.41 \\
\hline Mean & & 2.68 & & & & \\
\hline SD & & 3.88 & & & & \\
\hline Q1: 0-0.75 servings/week & 766 & & 13.89 & 4747 & $86 \cdot 11$ & \\
\hline Q2: $0.75-1.5$ servings/week & 671 & & $12 \cdot 06$ & 4895 & 87.94 & \\
\hline Q3: 1.5-3 servings/week & 631 & & $12 \cdot 24$ & 4523 & 87.76 & \\
\hline Q4: >3 servings/week & 632 & & 11.69 & 4776 & 88.31 & \\
\hline
\end{tabular}


Table 1. (Continued)

\begin{tabular}{|c|c|c|c|c|c|c|}
\hline \multirow[b]{2}{*}{ Variables } & \multicolumn{3}{|c|}{ Cases ( $n$ 8320) } & \multicolumn{2}{|c|}{ Non-cases ( $n 23231$ ) } & \multirow[b]{2}{*}{ Missing percentage } \\
\hline & $n$ & & $\%$ & $n$ & $\%$ & \\
\hline Vegetables and vegetable products & & & & & & 4.47 \\
\hline Mean & & 29.48 & & & & \\
\hline SD & & 47.94 & & & & \\
\hline Q1: 0-12 servings/week & 1992 & & $26 \cdot 29$ & 5585 & 73.71 & \\
\hline Q2: $12-17$ servings/week & 1629 & & 21.74 & 5864 & 78.26 & \\
\hline Q3: 17-29 servings/week & 1422 & & 18.86 & 6118 & $81 \cdot 14$ & \\
\hline Q4: >29 servings/week & 1590 & & $21 \cdot 12$ & 5940 & 78.88 & \\
\hline Fruits and fruit products & & & & & & $8 \cdot 16$ \\
\hline Mean & & 9.18 & & & & \\
\hline SD & & 9.97 & & & & \\
\hline Q1: 0-3 servings/week & 2056 & & 26.46 & 5715 & 73.54 & \\
\hline Q2: 3-6 servings/week & 1100 & & 14.79 & 6338 & $85 \cdot 21$ & \\
\hline Q3: 6-14 servings/week & 2019 & & 28.55 & 5052 & 71.45 & \\
\hline Q4: >14 servings/week & 1281 & & 18.69 & 5574 & 81.31 & \\
\hline Sugar and sugar products & & & & & & 30.52 \\
\hline Mean & & 10.99 & & & & \\
\hline SD & & 14.67 & & & & \\
\hline Q1: 0-1 servings/week & 667 & & $10 \cdot 40$ & 5745 & 89.60 & \\
\hline Q2: 1-4 servings/week & 438 & & $9 \cdot 37$ & 4236 & 90.63 & \\
\hline Q3: 4-10 servings/week & 641 & & 11.95 & 4725 & 88.05 & \\
\hline Q4: >10 servings/week & 896 & & 16.38 & 4573 & 83.62 & \\
\hline Beverages (non-milk) & & & & & & $4 \cdot 20$ \\
\hline Mean & & $56 \cdot 84$ & & & & \\
\hline SD & & 17.63 & & & & \\
\hline Q1: 0-28 servings/week & 2399 & & 23.90 & 7083 & $76 \cdot 10$ & \\
\hline Q2: 28-42 servings/week & 1491 & & 23.86 & 4579 & $76 \cdot 14$ & \\
\hline Q3: 42-62 servings/week & 1696 & & 24.15 & 5328 & 75.85 & \\
\hline Q4: >62 servings/week & 2570 & & 34.40 & 4901 & 65.60 & \\
\hline
\end{tabular}

* Age was coded as the original continuous values and six categorical values, food intakes were coded as quartile-order categorical values, and the other variables were coded as categorical dummy values.

†Q1-Q4: lowest intake to highest intake (servings/week).

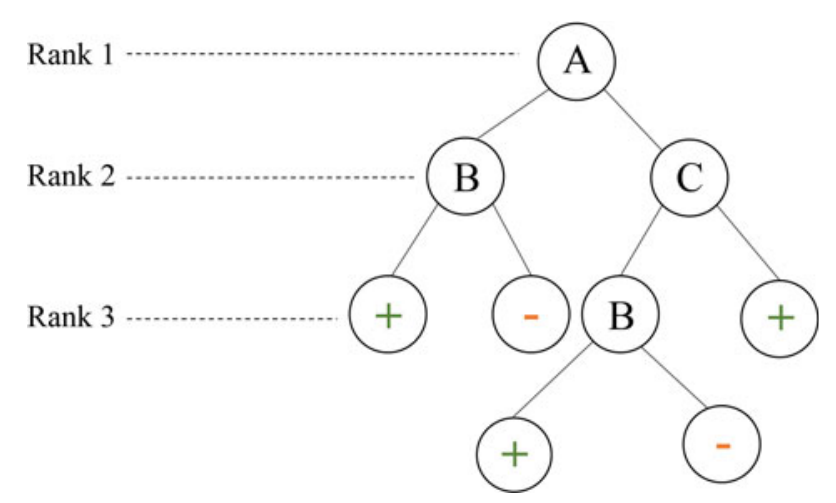

Fig. 1. Example of a decision tree. There are three individual variables, A, B and $\mathrm{C}$, on which the tree splits. Variable $\mathrm{A}$ has an average ranking of 1 because it is the root node and appears only once. Variable $B$ has an average ranking of 2.5, since it appears twice, once on the second and once on the third rank. Variable $\mathrm{C}$ has an average ranking of 2 , since it is present only once and the tree splits on it after it split on $\mathrm{A}$.

accuracy is $75 \cdot 10 \%$, with true positive rate 0.86 and false positive rate 0.31 (the receiver operating characteristic curves, with AUC from 0.690 to $0 \cdot 701$, for each cross-validation run were performed in online Supplementary Fig. S1).

Table 2 presents the extracted eight rules resulting into $\mathrm{BC}$ outcome after application of the 'ruleset' classifier of C5.0, with a classification accuracy of $74.90 \%$. The results from 'ruleset' show that the variables identified by the 'decision tree' approach are also identified by using the 'ruleset' approach. Here, we see that current/former male smokers tended to be BC cases and never male smokers tended to be non-BC cases. However, to be able to split the participants into case or non-case is depending on their dietary habits. Females show relatively simple rules, in which only 'grain and grain products' and 'beverages (non-milk)' were identified to be related to BC.

A sensitivity analysis by transforming age into categorical variable was performed based on the $\mathrm{C} 5.0$ algorithm; the results shown are similar to the identification of same food groups related to BC (online Supplementary Fig. S2).

\section{Discussion}

To our knowledge, this is among the first studies to apply the data mining approach to extract food groups associated with $\mathrm{BC}$ risk based on the complexity of the combinational food intake. By applying C5.0 algorithm, the decision tree and rules derived from this approach showed that sex, smoking status, age and five food groups (C: meats and meat products, E: fats, oils and their products, F: grains and grain products, H: vegetables and vegetable products, K: beverages (non-milk)) are in relation with $\mathrm{BC}$ risk in both males and females. Apart from the well-established factors (e.g. age, sex and smoking) for BC identified in the data mining procedures, the association of diet, especially specific dietary pattern, with $\mathrm{BC}$ risk deserves to be explored due to the limited evidence on this topic and because 
Table 2. Classification rules derived from C5.0 'Ruleset' in the BLadder cancer Epidemiology and Nutritional Determinants (BLEND) data set ${ }^{\star}$ (Percentages)

\begin{tabular}{|c|c|c|c|c|c|c|c|c|c|c|}
\hline Sex & Rules & Age (years) & Smoking status & $\mathrm{C}$ & $E$ & $\mathrm{~F}$ & $\mathrm{H}$ & $\mathrm{K}$ & Case (\%) & Non-case (\%) \\
\hline \multirow[t]{5}{*}{ Male } & 1 & & Current & & Q1† & Q3-Q4 & Q3-Q4 & Q1-Q2 & 24 & 76 \\
\hline & 2 & $40-63$ & Former & & & Q1 & & Q4 & 67 & 33 \\
\hline & 3 & & & Q3-Q4 & & Q1 & Q1-Q2 & & 87 & 13 \\
\hline & 4 & & Never & & & & & & 23 & 77 \\
\hline & 5 & & Current/former & & & & & & 63 & 37 \\
\hline \multirow[t]{2}{*}{ Female } & 6 & & & & & Q2-Q4 & & & 13 & 87 \\
\hline & 7 & & Former & & & Q1 & & Q1-Q2 & 80 & 20 \\
\hline
\end{tabular}

$\mathrm{C}$, meats and meat products; $\mathrm{E}$, fats, oils and their products; $\mathrm{F}$, grains and grain products; $\mathrm{H}$, vegetables and vegetable products; $\mathrm{K}$, beverage (non-milk).

${ }^{*}$ Age: years old; C-K: servings/week.

† Q1-Q4: lowest intake to highest intake (servings/week).

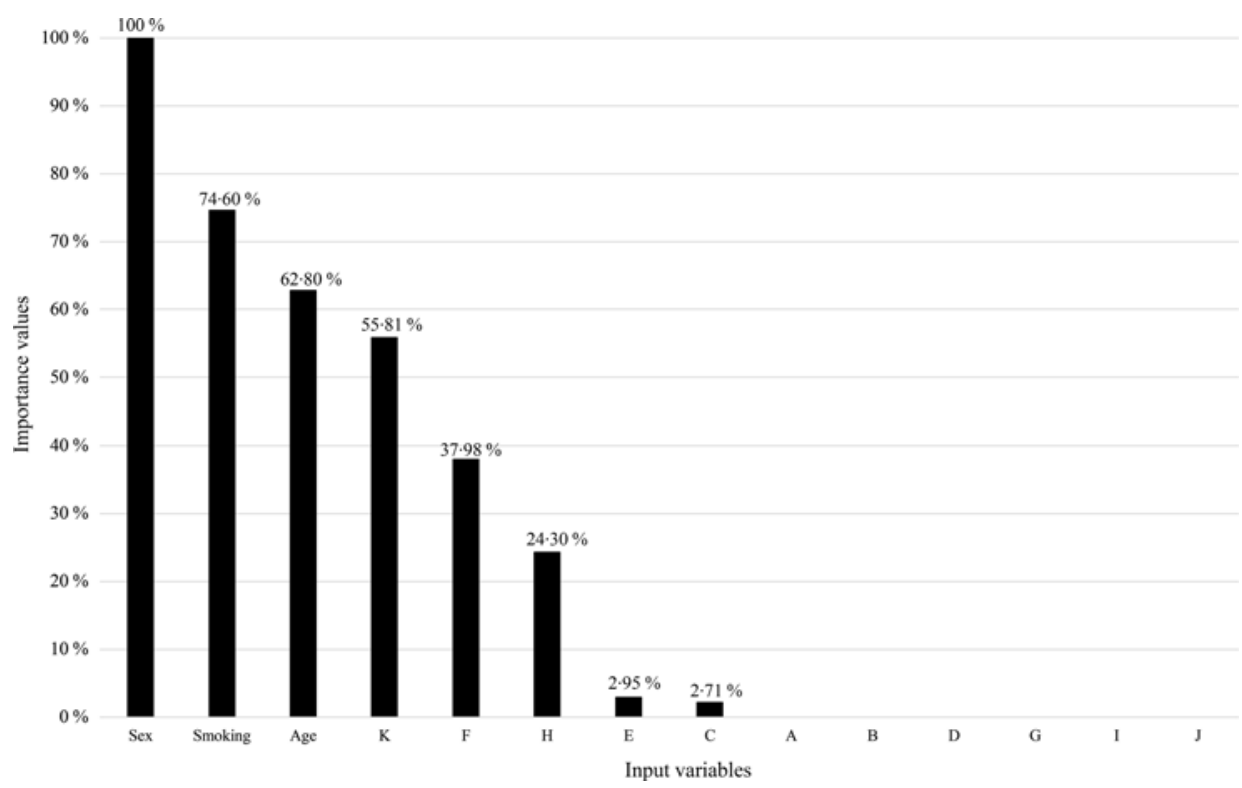

Fig. 2. Importance values of input variables after C5.0 in the BLEND data set. A: milk and dairy products; B: eggs and egg products; C: meats and meat products; $\mathrm{D}$ : fishes and fish products; $\mathrm{E}$ : fats, oils and their products; F: grains and grain products; G: pulses, seeds, kernels, nuts and their products; $\mathrm{H}$ : vegetables and vegetable products; I: fruits and fruit products; J: sugar and sugar products; K: beverages (non-milk). The importance values range from 0 to $100 \%$, where $0 \%$ indicates 'unimportant' and $100 \%$ indicates 'extremely important'.

it reflects a person's dietary exposure in aggregate rather than in isolation.

Although the use of data mining is relatively new for unravelling diet in relation to the cancer risk, previous studies already examined dietary intake with $\mathrm{BC}$ risk using other techniques. In 2008, De Stefani et $a l .{ }^{(43)}$ found that the dietary patterns labelled as 'sweet beverages' (high loadings of coffee, tea and added sugar) and 'Western' (high loadings of red meat, fried eggs, potatoes and red wine) were directly associated with the risk of $\mathrm{BC}$ based on factor analysis. In addition, the negative influence of the Western diet was also observed for $\mathrm{BC}$ recurrence: $\mathrm{BC}$ patients in the highest tertile of adherence to a Western dietary pattern had a $48 \%$ higher risk of recurrence of $\mathrm{BC}$ compared with patients in the lowest tertile ${ }^{(6)}$. The Western diet is especially low in fresh fruits and vegetables, but generally high in saturated fats and red and processed meats. Results from the present study are in line with these results, with respect to high intake of fat being associated with an increased risk for the development of $\mathrm{BC}$ and high intake of vegetables and vegetable products being associated with a reduced risk.

Previous studies on single food item or food groups in relation to $\mathrm{BC}$ risk also reported that high intake of vegetables was associated with reduced risk of $\mathrm{BC}^{(44-47)}$. These studies suggest that the preventive effect could possibly be due to the antioxidant action of vegetables ${ }^{(48,49)}$ and that each serving of vegetable may result in a $10 \%$ risk decline. Although very powerful, results from the present study only identify 'vegetables and vegetable products' as a possible main food group related to BC risk. It remains unclear which specific subgroup is responsible (e.g. starchy/non-starchy, processed/fresh, citrus/cruciferous). Detailed analyses of BLEND data may help to elucidate this uncertainty.

Limited evidence is available on the influence of 'grains and grain products' on $\mathrm{BC}$ risk. However, our findings are in line with results from a previously conducted case-control ${ }^{(50)}$, suggesting that a high intake of whole grains may reduce the risk of BC. 
In contrast, a more recent study found that $\mathrm{BC}$ risk was negatively influenced by a high intake of refined carbohydrate foods ${ }^{(51)}$. Thus, future detailed analyses, especially those focusing on whole grains and refined grain products, may be useful. Of note, our results on grain products might have been influenced by the fact that the 'grain and grain products' group of the present study included sweet 'Fine bakery wares', such as 'Sweet biscuits and cookies' which are high in sugar and thereby promote obesity, is known to be a risk factor for $\mathrm{BC}^{(52)}$.

Only few studies discussed the associations between fat, oil and their products and BC risk and were summarised in a systematic review. This review showed that the total fat intake was positively related to $\mathrm{BC}$ risk when combining results from three case-control studies. However, no such association was observed in cohort studies ${ }^{(53)}$. The present study confirms findings from the case-control studies, in that a positive association was found.

A meta-analysis reported that overall meat intake was not related to the risk of $\mathrm{BC}$; however, high red and processed meat intake was reported as a significant risk factor for BC risk, $17 \%$ and $10 \%$ risk, respectively ${ }^{(54)}$. This increase is probably caused by the $N$-nitroso compounds, which have been proposed as possible bladder carcinogens, found in red and processed meats ${ }^{(55)}$. In the present study, a high intake of 'meats and meat products (C)' was associated with an increased risk of developing BC. Again, future studies investigating specific types of meat could identify the types of meat or meat products that might have beneficial effects.

As an excretory organ, fluid intake might play an important role in the development of BC. A well-established risk factor is $\operatorname{arsenic}^{(56)}$, through which people are most likely exposed by drinking water. The influence of other fluid sources on BC risk, however, is lacking evidence or is inconstant. Here, we observed that high beverage intake is positively associated with $\mathrm{BC}$ risk. Again, it should be noted that only total 'beverage' intake was assessed, including both beverages with a potential protective effect on $\mathrm{BC}$ risk (e.g. green tea $\left.{ }^{(57)}\right)$ and beverages with a potential harmful effect on BC risk (e.g. alcoholic ${ }^{(58)}$ and sweet nonalcoholic beverages $\left.{ }^{(43)}\right)$. It, therefore, remains unclear which caused the observed increased BC risk.

Since nutrition and cancer epidemiology is a complex field, the use of advanced analytic tools, such as data mining, is becoming increasingly important for unrevealing diet and health associations. Data mining has demonstrated its potential to complement conventional statistical regressions, particularly for non-linear phenomena such as our dietary habits ${ }^{(59)}$, and without requiring a priori assumptions on the relationship between diet and health outcomes ${ }^{(60)}$. In addition, data mining splits data files into training and validation sets, especially using cross-validation method gives relatively accurate predictive estimates. Furthermore, overfitting problem of both decision tree and rules could be minimised by using a reduced error pruning technique in $\mathrm{C} 5.0^{(36)}$ which is often problematic in conventional statistical techniques with a large number of variables and observations, such as the BLEND data set. The strength of the present study is the high classification accuracy, which indicates the data mining methodology could adequately handle missing data and complex-investigating measurements. Therefore, the revealed food groups in the present study could be considered foods or pattern in relation to $\mathrm{BC}$ development.

A limitation of our study, however, is that the use of data mining in nutritional cancer epidemiology might only be useful in identifying key food items and can therefore only be seen as a hypothesis generator, which needs further detailed investigation in order to establish causation. Furthermore, we should acknowledge it is a complicated technique, which requires special knowledge and expertise, and thus, translating the results from data mining into simple health message is a difficult challenge. In addition, the trees and rules retrieved in the present study only include main food groups; thereby, conflicting effects on $\mathrm{BC}$ risk of food subgroups or specific items was inevitable. Another limitation might have occurred by the designs of the data collection, which may have introduced recall and/or selection bias, especially in case-control studies. In addition, for most included studies, the exposure variable was assessed by FFQ. Therefore, measurement error and misclassification of study participants in terms of the exposure and outcome are unavoidable: a) the inability of an FFQ to capture many details of dietary intake, such as all kinds and exact amounts of foods consumed, b) the difficulty in quantification of the intake and c) the high dependency on memory, which in turn may have influenced the robustness of dietary patterns extracted via the data mining procedure $^{(61)}$. Lastly, due to the nature of data mining such as C5.0, there are concerns regarding multiple testing and spurious associations, which might cause some of the observed consequences due to chance alone.

\section{Conclusion}

In summary, the data mining technique provided an effective approach to identify some food groups related to BC risk in the large epidemiological BLEND study. The main findings from this study support the data mining approach to be a valuable additional methodology in nutrition and cancer epidemiology, which deserve further examination.

\section{Disclaimer}

Where authors are identified as personnel of the International Agency for Research on Cancer/World Health Organization, the authors alone are responsible for the views expressed in this article and they do not necessarily represent the decisions, policy or views of the International Agency for Research on Cancer/ World Health Organization.

\section{Acknowledgements}

We gratefully acknowledge all principal investigators for their willingness to participate in this jointed project. The author E. Y. W. Y. gives thanks to the financial support from China Scholarship Council (no. 201706310135).

This work was partly funded by the World Cancer Research Fund International (WCRF 2012/590) and European Commission (FP7-PEOPLE-618308).

The Hessen case-control study on bladder cancer was supported by the Bundesanstalt für Arbeitsschutz (no. F 1287). 
The Kaohsiung study was supported by grant NSC 85-2332-B037-066 from the National Scientific Council of the Republic of China. The Stockholm case-control study was supported by grant from the Swedish National Cancer Society and from the Swedish Work Environment Fund. The Roswell Park Memorial Institute case-control study on bladder cancer was supported by Public Health Service grants CA11535 and CA16056 from the National Cancer Institute. The New England bladder cancer study was funded in part by grant numbers 5 P 42 ES007373 from the National Institute of Environmental Health Sciences, NIH and CA57494 from the National Cancer Institute, NIH. The Italian case-control study on bladder cancer was conducted within the framework of the CNR (Italian National Research Council) Applied Project 'Clinical Application of Oncological Research' (contracts 94.01321.PF39 and 94.01119.PF39), and with the contributions of the Italian Association for Cancer Research, the Italian League against Tumours, Milan, and Mrs. Angela Marchegiano Borgomainerio. The Brescia bladder cancer study was partly supported by the International Agency for Research on Cancer. The French INSERM study was supported by a grant from the Direction Générale de la Santé, Ministère des Affaires Sociales, France. The Molecular Epidemiology of Bladder Cancer and Prostate Cancer was supported in part by grants ES06718 (to Z.-F. Z.), U01 CA96116 (to A. B.), and CA09142 from the NIH National Institute of Environmental Health Sciences, the National Cancer Institute, the Department of Health and Human Services, and by the Ann Fitzpatrick Alper Program in Environmental Genomics at the Jonsson Comprehensive Cancer Center, UCLA. The Women's Lifestyle and Health Study was funded by a grant from the Swedish Research Council (grant number 521-2011-2955). The Netherlands Cohort Study on diet and cancer was supported by the Dutch Cancer Society. The RERF atomic bomb survivors study was supported by The Radiation Effects Research Foundation (RERF), Hiroshima and Nagasaki, Japan, a public interest foundation funded by the Japanese Ministry of Health, Labour and Welfare (MHLW) and the USA Department of Energy (DOE). The research was also funded in part through DOE award DE-HS0000031 to the National Academy of Sciences. This publication was supported by RERF Research Protocol RP-A5-12. The VITamins and Lifestyle Study (VITAL) was supported by a grant (R01CA74846) from the National Cancer Institute.

Study conception and design: A. W. and M. P. Z.; analyses and interpretation of data: E. Y. Y. and C. S.; drafting of the manuscript: E. Y. Y.; revised the manuscript: A. W. and M. P. Z.; provided the data and revised the manuscript: A. W., M. C. S., X. J., L. T., J. M., E. K., P. v. d. B., C. M. L., H. P., G. S., M. F. A., M. R. K., C. L. V., S. P., A. C., K. G., K. C. J., S. B., Z. F. Z., C. B., J. A. T., E. W., E. J. G., E. W. and J. P.; approved the manuscript: all authors.

All the authors declare no conflicts of interest.

\section{Supplementary material}

For supplementary material referred to in this article, please visit https://doi.org/10.1017/S0007114520001439

\section{References}

1. Ferlay J, Soerjomataram I, Dikshit R, et al. (2015) Cancer incidence and mortality worldwide: sources, methods and major patterns in GLOBOCAN 2012. Int J Cancer 136, E359-E386.

2. Siegel RL, Miller KD \& Jemal A (2017) Cancer statistics. $C A$ Cancer J Clin 67, 7-30.

3. Al-Zalabani AH, Stewart KF, Wesselius A, et al. (2016) Modifiable risk factors for the prevention of bladder cancer: a systematic review of meta-analyses. Eur J Epdemiol 31, 811-851.

4. Piyathilake C (2016) Dietary factors associated with bladder cancer. Invest Clin Urol 57, Suppl. 1, S14-S25.

5. Wiseman M, World Cancer Research Fund/American Institute for Cancer Research (2018) Diet, Nutrition, Physical Activity and Cancer: A Global Perspective. Continuous Update Project Expert Report 2018. https://www.wcrf.org/sites/ default/files/Summary-of-Third-Expert-Report-2018.pdf

6. Westhoff E, Wu X, Kiemeney LA, et al. (2018) Dietary patterns and risk of recurrence and progression in non-muscle-invasive bladder cancer. Int J Cancer 142, 1797-1804.

7. Witlox WJA, van Osch FHM, Brinkman M, et al. (2020) An inverse association between the Mediterranean diet and bladder cancer risk: a pooled analysis of 13 cohort studies. Eur J Nutr 59, 287-296.

8. Han J \& Kamber M (2001) Getting to know your data. In Data Mining Concepts and Techniques, pp. 70-72. Amsterdam: Elsevier.

9. Hearty AP \& Gibney MJ (2008) Analysis of meal patterns with the use of supervised data mining techniques - artificial neural networks and decision trees. Am J Clin Nutr 88, 1632-1642.

10. Goossens ME, Isa F, Brinkman M, et al. (2016) International pooled study on diet and bladder cancer: the BLadder cancer, Epidemiology and Nutritional Determinants (BLEND) study: design and baseline characteristics. Arch Public Health 74, 30.

11. Bernstein L \& Ross R (1991) Cancer in Los Angeles County. Los Angeles, CA: University of Southern California.

12. Tang L, Zirpoli GR, Guru K, et al. (2008) Consumption of raw cruciferous vegetables is inversely associated with bladder cancer risk. Cancer Epidemiol Prevent Biomarkers 17, 938-944.

13. Kellen E, Zeegers M, Lousbergh D, et al. (2005) A Belgian case control study on bladder cancer: rationale and design. Arch Public Health 63, 17-34.

14. Wakai K, Takashi M, Okamura K, et al. (2000) Foods and nutrients in relation to bladder cancer risk: a case-control study in Aichi Prefecture, Central Japan. Nutr Cancer 38, 13-22.

15. Lu C-M, Lan S-J, Lee Y-H, et al. (1999) Tea consumption: fluid intake and bladder cancer risk in Southern Taiwan. Urology $\mathbf{5 4}$, 823-828.

16. Pohlabeln H, Jöckel K-H \& Bolm-Audorff U (1999) Nonoccupational risk factors for cancer of the lower urinary tract in Germany. Eur J Epidemiol 15, 411-419.

17. Steineck G, Hagman U, Gerhardsson M, et al. (1990) Vitamin A supplements, fried foods, fat and urothelial cancer. A casereferent study in Stockholm in 1985-87. Int J Cancer 45, 1006-1011.

18. Mettlin C \& Graham S (1979) Dietary risk factors in human bladder cancer. Am J Epidemiol 110, 255-263.

19. Baena AV, Allam MF, Del Castillo AS, et al. (2006) Urinary bladder cancer risk factors in men: a Spanish case-control study. Eur J Cancer Prevent 15, 498-503.

20. Brinkman MT, Karagas MR, Zens MS, et al. (2010) Minerals and vitamins and the risk of bladder cancer: results from the New Hampshire Study. Cancer Causes Control 21, 609-619. 
21. D’Avanzo B, La Vecchia C, Negri E, et al. (1995) Attributable risks for bladder cancer in northern Italy. Ann Epidemiol 5, 427-431.

22. Shen M, Hung RJ, Brennan P, et al. (2003) Polymorphisms of the DNA repair genes XRCC1, XRCC3, XPD, interaction with environmental exposures, and bladder cancer risk in a casecontrol study in northern Italy. Cancer Epidemiol Prevent Biomarkers 12, 1234-1240.

23. Johnson K, Mao Y, Argo J, et al. (1998) The National Enhanced Cancer Surveillance System: a case-control approach to environment-related cancer surveillance in Canada. Environmetrics 9, 495-504.

24. Ovsiannikov D, Selinski S, Lehmann M-L, et al. (2012) Polymorphic enzymes, urinary bladder cancer risk, and structural change in the local industry. J Toxicol Environ Health Part A 75, 557-565.

25. Clavel J \& Cordier S (1991) Coffee consumption and bladder cancer risk. Int J Cancer 47, 207-212.

26. Hemelt $\mathrm{M}, \mathrm{Hu} Z$, Zhong Z, et al. (2010) Fluid intake and the risk of bladder cancer: results from the South and East China case-control study on bladder cancer. Int J Cancer 127, 638-645.

27. Cao W, Cai L, Rao JY, et al. (2005) Tobacco smoking, GSTP1 polymorphism, and bladder carcinoma. Cancer 104, 2400-2408.

28. Taylor JA, Umbach DM, Stephens E, et al. (1998) The role of $\mathrm{N}$-acetylation polymorphisms in smoking-associated bladder cancer: evidence of a gene-gene-exposure three-way interaction. Cancer Res 58, 3603-3610.

29. van den Brandt PA, Goldbohm RA, van 't Veer P, et al. (1990) A large-scale prospective cohort study on diet and cancer in The Netherlands. J Clin Epidemiol 43, 285-295.

30. Poortvliet E, Klensin J \& Kohlmeier L (1992) Rationale document for the Eurocode 2 food coding system (version 91/2). Eur J Clin Nutr 46, S9-S24.

31. Hastie T, Tibshirani R \& Friedman J (2009) Unsupervised learning. In The Elements of Statistical Learning, vol. 2, pp. 485-585 [R Tibshirani, editor]. New York: Springer.

32. Rubin DB (1976) Inference and missing data. Biometrika 63 581-592.

33. Van Ness PH, Murphy TE, Araujo KL, et al. (2007) The use of missingness screens in clinical epidemiologic research has implications for regression modeling. J Clin Epidemiol 60, $1239-1245$.

34. Little RJ (1988) A test of missing completely at random for multivariate data with missing values.J Am Stat Assoc 83, 1198-1202.

35. Li C (2013) Little's test of missing completely at random. Stata J 13, 795-809.

36. Pandya R \& Pandya J (2015) C5. 0 algorithm to improved decision tree with feature selection and reduced error pruning. Int J Comput Appl 117, 18-21.

37. Quinlan JR (2014) C4. 5: Programs for Machine Learning. Waltham, MA: Elsevier.

38. Quinlan JR (1989) Unknown attribute values in induction. In Proceedings of the Sixth International Workshop on Machine Learning, December 1989, pp. 164-168. San Francisco, CA: Morgan Kaufmann

39. Karaolis M, Moutiris JA \& Pattichis CS (2008) Assessment of the risk of coronary heart event based on data mining. BIBE 2008 8th IEEE International Conference on BioInformatics and BioEngineering, pp. 1-5. Piscataway, NJ, IEEE.

40. Lazarou C, Karaolis M, Matalas A-L, et al. (2012) Dietary patterns analysis using data mining method. An application to data from the CYKIDS study. Comput Meth Prog Bio 108, 706-714.
41. Friedman J, Hastie T \& Tibshirani R (2001) The Elements of Statistical Learning, vol. 1. Springer Series in Statistics. New York: Springer.

42. Louppe G, Wehenkel L, Sutera A, et al. (2013) Understanding variable importances in forests of randomized trees. Adv Neural Inf Process Syst 26, 431-439.

43. De Stefani E, Boffetta P, Ronco AL, et al. (2008) Dietary patterns and risk of bladder cancer: a factor analysis in Uruguay. Cancer Causes Control 19, 1243-1249.

44. Xu C, Zeng XT, Liu TZ, et al. (2015) Fruits and vegetables intake and risk of bladder cancer: a PRISMA-compliant systematic review and dose-response meta-analysis of prospective cohort studies. Medicine (Baltimore) 94, e759.

45. Vieira AR, Vingeliene S, Chan DS, et al. (2015) Fruits, vegetables, and bladder cancer risk: a systematic review and meta-analysis. Cancer Med 4, 136-146.

46. Liu H, Wang XC, Hu GH, et al. (2015) Fruit and vegetable consumption and risk of bladder cancer: an updated metaanalysis of observational studies. Eur J Cancer Prev 24, 508-516.

47. Yao B, Yan Y, Ye X, et al. (2014) Intake of fruit and vegetables and risk of bladder cancer: a dose-response meta-analysis of observational studies. Cancer Causes Control 25, $1645-1658$.

48. Boeing H, Bechthold A, Bub A, et al. (2012) Critical review: vegetables and fruit in the prevention of chronic diseases. EurJ Nutr 51, 637-663.

49. Riboli E \& Norat $T$ (2003) Epidemiologic evidence of the protective effect of fruit and vegetables on cancer risk. Am J Clin Nutr 78, 559S-569S.

50. Chatenoud L, Tavani A, La Vecchia C, et al. (1998) Whole grain food intake and cancer risk. Int J Cancer 77, 24-28.

51. Augustin LSA, Taborelli M, Montella M, et al. (2017) Associations of dietary carbohydrates, glycaemic index and glycaemic load with risk of bladder cancer: a case-control study. Br J Nutr 118, 722-729.

52. Sun JW, Zhao LG, Yang Y, et al. (2015) Obesity and risk of bladder cancer: a dose-response meta-analysis of 15 cohort studies. PLOS ONE 10, e0119313.

53. La Vecchia C \& Negri E (1996) Nutrition and bladder cancer. Cancer Causes Control 7, 95-100.

54. Wang C \& Jiang H (2012) Meat intake and risk of bladder cancer: a meta-analysis. Med Oncol 29, 848-855.

55. Catsburg CE, Gago-Dominguez M, Yuan JM, et al. (2014) Dietary sources of $\mathrm{N}$-nitroso compounds and bladder cancer risk: findings from the Los Angeles Bladder Cancer Study. Int J Cancer 134, 125-135.

56. Baris D, Waddell R, Beane Freeman LE, et al. (2016) Elevated bladder cancer in Northern New England: the role of drinking water and arsenic. J Natl Cancer Inst 108, djw099.

57. Miyata Y, Matsuo T, Araki K, et al. (2018) Anticancer effects of green tea and the underlying molecular mechanisms in bladder cancer. Medicines (Basel) 5, 87.

58. Vartolomei MD, Iwata $\mathrm{T}$, Roth $\mathrm{B}$, et al. (2019) Impact of alcohol consumption on the risk of developing bladder cancer: a systematic review and meta-analysis. World J Urol 37, $2313-2324$

59. Huys R \& Jirsa VK (2010) Nonlinear Dynamics in Human Behavior, vol. 328. New York: Springer.

60. Crutzen R \& Giabbanelli P (2013) Using classifiers to identify binge drinkers based on drinking motives. Subst Use Misuse 49, 110-115.

61. Rodrigo CP, Aranceta J, Salvador G, et al. (2015) Food frequency questionnaires. Nutr Hosp 31, 49-56. 